\title{
Nutritional and Health Benefits of Carrots and Their Seed Extracts
}

\author{
João Carlos da Silva Dias \\ Instituto Superior de Agronomia, University of Lisbon, Lisboa, Portugal \\ Email: mirjsd@gmail.com
}

Received 7 October 2014; revised 29 October 2014; accepted 15 November 2014

Copyright (C) 2014 by author and Scientific Research Publishing Inc.

This work is licensed under the Creative Commons Attribution International License (CC BY). http://creativecommons.org/licenses/by/4.0/

(c) (i) Open Access

\begin{abstract}
Carrot is a root vegetable with carotenoids, flavonoids, polyacetylenes, vitamins, and minerals, all of which possess numerous nutritional and health benefits. Besides lending truth to the old adage that carrots are good for eyes, carotenoids, polyphenols and vitamins present in carrot act as antioxidants, anticarcinogens, and immunoenhancers. Anti-diabetic, cholesterol and cardiovascular disease lowering, anti-hypertensive, hepatoprotective, renoprotective, and wound healing benefits of carrot have also been reported. The cardio- and hepatoprotective, anti-bacterial, anti-fungal, anti-inflammatory, and analgesic effects of carrot seed extracts are also noteworthy. All are discussed in this review article.
\end{abstract}

\section{Keywords}

Daucus carota, Chemical Composition, Antioxidants, Phytochemicals, Disease Prevention

\section{Introduction}

Carrot (Daucus carota L.) is the most important crop of Apiaceae family. It is a root vegetable that has worldwide distribution. Carrots were first used for medical purposes and gradually used as food. Written records in Europe indicated that carrots were cultivated prior to the tenth century. The colors of the carrot root flesh may be white, yellow, orange, red, purple, or very dark purple. The first cultivated carrots were yellow and purple fleshed cultivars. Orange carrots, today more popular, were developed in the 15th and 16th centuries in Central Europe. A rapid rise in the popularity of orange carrots was observed with the recognition of its high provitamin A content [1]. Carotenoids and anthocyanins are the major antioxidant pigments found in carrots. Cultivar differences in carrots rely in the type of pigments present. Carotenoids are the yellow, orange, or red colored phytochemicals found in most yellow and orange fleshed cultivars. The widely used orange carrot is high in $\alpha$ - and $\beta$-carotene and is a rich source of provitamin A. Yellow carrot color is due to lutein which plays an important 
role in prevention of macular degeneration [2] [3]. The red water-soluble anthocyanin pigment and the red waterinsoluble lycopene pigment present in the roots of some cultivars do not contribute to the provitamin A content. Red carrot color is due to its high lycopene content [3]. Meanwhile anthocyanin-rich carrots are purple [4]. White flesh cultivars contain very little pigments. The carotene content of the orange and yellow fleshed cultivars increases with growth. The cortical region contains more carotenes than the core. Overall carotenoid levels, have increased dramatically in the past four decades through traditional breeding to reach levels of $1000 \mathrm{ppm}$ carotenoids, on a fresh weight basis [2] [3] [5]. Besides, comparing to other vegetables, carrots can provide in the human diet significant amount of vitamin A due to the high bioavailability of carrot carotenoids [6].

Carrots have also a unique combination of three flavonoids: kaempferol, quercetin and luteolin [7]-[9]. They are also rich in other phenols, including chlorogenic, caffeic and p-hydroxybenzoic acids along with numerous cinnamic acid derivates. Among hydroxycinnamic acid and its derivates, chlorogenic acid represents $42.2 \%$ to 61.8\% of total phenolic compounds detected in different carrot tissues [10] [11]. Bioactive polyacetylenes, such as falcarinol (synonymous with panaxynol), and falcarindiol are found in carrots. The concentration of falcarinol in fresh carrots depends on carrot tissue cultivar and water stress [12]. Falcarinol is the most bioactive phytochemical of the carrot polyacetylenes. It is though that this compound may stimulate cancer-fighting mechanisms in the human body. The mode of action behind the favorable effect of falcarinol may be due to its hydrophobicity and its ability to form an extremely stable carbocation with the loss of water thereby acting as a very reactive alkylating agent toward proteins and other biomolecules [13]. Besides other sesquiterpenes, which presence has also been found in various biochemical analyses, daucuside and daucuso are sesquiterpenoids recently isolated from carrot seeds and that have cytotoxic effect against human gastric cell lines [14] [15]. The presence of coumarins has also been demonstrated in various biochemical analysis. A bitter coumarin compound is formed when carrots are stored [16].

Among 39 fruits and vegetables carrots have been ranked 10th in nutritional value [17]. Carrot is a good source of dietary fiber and of the trace mineral molybdenum, rarely found in many vegetables. Molybdenum aids in metabolism of fats and carbohydrates and is important for absorption of iron. It is also a good source of magnesium and manganese. Magnesium is needed for bone, protein, making new cells, activating B vitamins, relaxing nerves and muscles, clotting blood, and in energy production [18]. Insulin secretion and function also require magnesium [19] [20]. Manganese is helpful in carbohydrate metabolism, in coordination with enzymes in the body [2] [3]. Manganese is used by the body as a co-factor for the antioxidant enzyme, superoxide dismutase. Potassium and magnesium in carrots help in functioning of muscles.

When carrot roots after juvenile stage are subjected to cold temperatures, for a period of time according to cultivars, flower induction and seedstalk formation takes place. Seeds contain essential oils. Carrot seed oil extracts have also health benefits. This article reviews the nutritional and health benefits of carrots and their seed extracts.

\section{Health Benefits of Carrots}

\subsection{Antioxidant, Anticarcinogen, and Immunoenhancer Benefits}

Like many other colored vegetables carrot is a gold mine of antioxidants. Carotenoids, polyphenols and vitamins present in carrot act as antioxidants, anticarcinogens, and immunoenhancers. Carotenoids widely distributed in orange carrots are potent antioxidants which can neutralize the effect of free radicals. They have been shown to have inhibition mutagenesis activity contributing to decrease risk of some cancers [2] [3]. Zhang and Hamauzuet [10] reported that flavonoids and phenolic derivates, present in carrot roots play also an important role as antioxidants. They also exert anticarcinogenic activities, reduce inflammatory insult, and modulate immune response [2] [3].

Zaini et al. [21] reported the anti-carcinogenic effect of carrot juice extracts on myeloid and lymphoid leukemia cell lines. In vitro analysis was done on 72 hours incubation of carrot juice extracts in leukemia cell lines and non-tumor control cells. It was observed that carrot juice extract possessed the ability to induce apoptosis and cause cell cycle arrest in leukemia cell lines. The effect was less prominent in myeloid and hematopoietic stem cells. Those investigators considered that $\beta$-carotene and falcarinol present in the carrot juice extract may have been responsible for this beneficial effect of "kill" leukemia cells and inhibit their progression.

Darroudi et al. [22] reported the anti-clastogenic activity of carrot on Chinese hamster ovary (CHO) cells and human lymphocytes. In pre-treated rats, fresh carrot juice was shown to attenuate the increase in the frequencies 
of sister-chromatid exchanges induced by cyclophosphamide in wild-type and mutant CHO cells.

Larsen et al. [23] investigated the impact of carrot and its constituent falcarinol against development of azoxymethane (AOM)-induced colon preneoplastic lesions in rat colon. Rats were assorted and treated with AOM and fed with carrot and falcarinol isolated from carrot. The results showed that there was a significant reduction in tumors and aberrant crypt foci (ACF) in rats fed with carrot and falcarinol. The investigators concluded that this evidence indicates that dietary treatment with carrot and falcarinol has the potential to delay or retard the development of large ACF and colon tumors.

Purup et al. [24] reported that extracts of carrot which contain different amounts of falcarinol, falcarindiol, and falcarindiol 3-acetate had significant inhibithory effects on both normal and cancer cell proliferation. The study suggests that the aliphatic C17-polyacetylenes are the potential anti-cancer principles of carrots and that the synergistic interation between bioactive polyacetylenes may be important for their bioactivity. Other studies have reported that falcarinol exerts cytotoxic activity against several human tumor cell lines in vitro, destroying pre-cancerous cells in the tumors [25] [26].

Ekam et al. [27] assessed the immunomodullatory effect of carrot-extracted carotenoid using 24 albino rats. The percentage variation in lymphocytes, eosinophils, monocytes and platelet count was evaluated. Interestingly, carotenoid administered rats showed a significant increase in lymphocytes, eosinoplils, monocytes and platelet concentration. The beneficial effect was due to carrot's $\alpha$ - and $\beta$-carotenoids.

A deficiency in vitamin A can cause eye's photoreceptors to deteriorate, which leads to vision problems. $\beta$ carotene (the carotenoid with the most provitamin A activity) in carrots helps to protect vision, especially night vision and also provides protection against macular degeneration and development of senile cataract, the leading cause of blindness in aged people [2] [3]. Eating carrots rich in $\beta$-carotene may restore vision, lending truth to the old adage that carrots are good for your eyes. Carrots are one of the richest sources of provitamin A and a hight intake of carotenoids linked with a significant decrease in post-menopausal breast cancer [28]. Research has shown also that smokers who eat carrots more than once a week have a lower risk of lung cancer [29], while a $\beta$-carotene rich diet may also protect against prostate cancer [30]. The curative effect of carotenoids and antioxidant polyphenols, and dietary fibers against bladder cancer and other carcinomas has also been reported by Hung et al. [31].

Carotenoids of carrots that have no vitamin A activity (lycopen, lutein, and zeaxanthin) may shrink also a diabetic's risk of developing diabetic retinopathy since as observed recently type 2 diabetics who had lower levels of no vitamin A activity carotenoids, lycopene, lutein and zeaxanthin, had corresponding higher levels of retinopathy [2] [3] [32].

Besides cart loads of $\beta$-carotene and other carotenoids, carrots contain vitamins such as vitamin $\mathrm{C}$ and $\mathrm{K}$, thiamin (B1), riboflavin (B2), pyridoxine (B6) and folates (B9), necessary for metabolism of carbohydrates, proteins and healthy growth [2] [3] [33]. Vitamin $C$ promotes the absorption of non-heme iron and is required for fighting infections and vitamin K helps preventing bleeding. Thiamin (B1) has highly beneficial effects on our nervous system and mental attitude; riboflavin is necessary for cell respiration, and red blood cell formation; pyridoxine inhibits the formation of homocysteine and reduces the risk of heart disease; and folates may reduce the risk of heart attack by lowering homocysteine levels. High levels of homocysteine have been found to be associated with an increased risk of hardening of arteries due to the accumulation of fatty plaques. It also protects against birth defects in babies [2] [3].

\subsection{Anti-Diabetic, Cholesterol and Cardiovascular Disease Lowering and Anti-Hypertensive Benefits}

Nutritionist generally recommend eating carrots in moderation because they contain more sugar than any other vegetable. This recommendation was based on the first journal article ever published on the carrot glycemic index (GI), in 1981, indicated that we quickly digest the carbohydrates in carrots. That study showed the carrots had a GI of 92 (where glucose $=100$ ). A later study that got much less attention showed the carrots had a GI of $39 \pm 7$ and the carrot juice of $45 \pm 4$ (Cale not pub). Recent research [34] demonstrates a significant association between vitamin A-rich carotenoids and diabetes status. According to these investigators higher blood glucose levels, as well as higher fasting levels of insulin, were observed in study participants with lower level of carotenoids. Carotenoid levels also decreased as the severity of glucose intolerance increased. These findings suggest that carrot and vitamin A-rich carotenoids might help diabetics to manage their condition. Chau et al. [35] comparing the 
characteristics, properties and in vitro hypoglycemic effects of various carrot water insoluble fiber-rich fractions, observed that dietary fiber-rich fractions, which contained not only water insoluble dietary fiber but also alcohol and water insoluble solides, isolated from carrot pomace exhibited glucose-adsorption capacity and amylase inhibition activity. Dietary fiber transports also a significant amount of polyphenols and carotenoids linked to the fibre matrix though the human gut [36] [37]. Chau et al. [35] concluded that the enhanced glucose adsorbance capacity and reduction of amylase activity of dietary fiber of carrot might help control post-prandial serum glucose level. This study confirmed the strong relationship between dietary fiber intake and lower risk of type 2 diabetes [2] [3]. Several mechanisms have been proposed for this inhibition, including improved insulin sensivity and/or decrease insulin requirement [38]. More recently Poudyal et al. [39] reported the efficacy of purple carrot juice against metabolic syndrome. Purple carrot diet was supplemented in a high-carbohydrate, high-fat diet-fed rat model. Interestingly, there was a reduction in impaired glucose tolerance, endothelial function and abdominal fat deposits. The purple carrot juice was rich in anthocyanin and low in carotenoids. Authors concluded that the anthocyanins of the carrot juice were responsible for the beneficial effect.

Nicolle et al. [40] reported that carrot showed cholesterol absorption mitigating effects in experimental carrot fed rats. Regulation in bile acid secretion and antioxidant status was also reported. A significant decrease in liver cholesterol and triglyceride levels was also observed by these investigators. Moreover, carrot consumption increased the vitamin E level in plasma and increased the ferric reducing ability of plasma [40]. In another study these authors administered lyophilized carrot enriched diet to mice. They observed that carrot ingestion decrease lipemia and improved antioxidant status in mice. Also, it improved the level of vitamin E and myocardial cells. The results suggested that carrot intake may exert a protective effect against cardiovascular disease linked to atherosclerosis. The effect may be due to the synergistic action of dietary fiber and antioxidant polyphenols in carrot [40]. The consumption of carrots has also been associated with lower risk of heart attacks in women [41]. In a recent study Griep et al. [42] examined the associations between fruit and vegetables of different colors and their subgroups and 10-year coronary heart disease (CHD) incidence. They used data from a prospective population-based cohort including 20,069 men and women aged 20 - 65 years who were enrolled between 1993 and 1997. They observed that eating more deep-orange-colored fruits and vegetables is associated with a lower risk of CHD. In particular, carrots (their largest contributor to total orange fruit and vegetables consumption with $60 \%$ ), were associated with a 32\% lower risk of CHD. They concluded that "a higher intake of deep orange fruit and vegetables, and especially carrots, may protect against CHD”.

Gilani et al. [43] studied the anti-hypertensive effect of two cumarin glycosides (DC-2 and DC-3) from carrots. Dose dependent intravenous administration of these glycoside compounds caused a decrease in arterial blood pressure in normotensive anaesthetized rats. Moreover, in vitro studies by the same investigators showed that the glycoside compounds caused inhibitory effects on spontaneously beating guinea pig atria, as well as on the kt-induced contractions of rabbit aorta. The authors concluded that the decreased blood pressure observed in in vitro studies may be due to the calcium channel blocking action of cumarin glycosides (DC-2 and DC-3) from carrots.

\subsection{Hepatoprotective, and Renoprotective Benefits}

Bishayee et al. [44] observed that carrot extract help to protect liver from acute injury by the toxic effects of environmental chemicals. In its study the effect of carrot extract on carbon tetrachloride (CC14)-induced acute liver damage in mouse was evaluated. The increased serum enzyme levels by CC14-induction were significantly lowered due to pre-treatment with the carrot extract. The carrot extract also decreased the elevated serum bilirubin and urea content due to CC14 administration. Increased activities of hepatic 5'-nucleotidase, acid phosphatase, acid ribonuclease and decreased levels of succinic dehydrogenase, glucose-6-phosphatase and cytochrome P-450 produced by $\mathrm{CCl} 4$ were reversed by the carrot extract in a dose-responsive way. The investigators concluded that results of this study revealed that carrot could afford a significant protective action in the alleviation of CCl4induced hepatocellular acute injury. Mills et al. [45] measured the possible effects of bioactive compounds in 4 biofortified flesh carrot cultivars (purple/orange, purple/orange/red, orange/red, and orange) on the provitamin A bioefficacy and antioxidant potential on the liver of Mongolian gerbils. Following a 4-wk vitamin A depletion period and baseline kill, freeze-dried carrot powders were mixed into purified feeds and fed to 6 groups of 11 Mongolian gerbils for $4 \mathrm{wk}$. White flesh carrot fed control and vitamin A supplemented groups were used to calculate carrot provitamin A bioefficacy. Antioxidant potential of carrot powders, sera, and livers were determined using the 2, 2'-azinobis-(3-ethylbenzothiazoline-6-sulfonic acid) radical cation decolorization assay and 
carotenoid and retinol concentrations were determined by HPLC. The authors observed that the antioxidant potential of the liver and vitamin A stores were greater in Mongolian gerbils fed with colored flesh carrots compared with the control gerbils fed with white flesh carrots and vitamin A supplemented groups.

Mital et al. [46] studied the renoprotective activity of carrot root extract on renal ischemia reperfusion acute injury in rats. Rats with renal reperfusion injury showed significantly decreased activity of superoxide dismutase, catalase and glutathione, and a significant increase in malondialdehyde level. The study revealed that carrot extract exerts renoprotective activity against ischemia reperfusion induced kidney acute injury, by reducing free radical scavenging activity one of the mechanisms behind ischemia reperfusion damage of kidneys.

\subsection{Wound Healing Benefits}

Patil et al. [47] report that animals treated with topical cream of ethanolic extract of carrot root, formulated at different concentrations, showed significant decreases in wound area, epithelization period and scar width when compared to control group animals in an excision wound model. Meanwhile, rate of wound contraction significantly increased. Moreover, there were also significant increases in wound tensile strength, hydroxyproline content and protein content in animals treated with the topical cream formulation of ethanolic extract of carrot seeds. The antioxidant and anti-microbial activities of ethanolic extract of carrot root, mainly flavonoids and phenolic derivates, may be involved in this increased curative property. Wound healing effects may also be due to regulation of collagen expression and inhibition of elevated levels of lipid peroxides.

\section{Health Benefits of Seed Carrot Extracts}

Seed carrot extracts and its essential oil have been reported in experimental studies to have cardio- and hepatoprotective, cognitive dysfunction, cholesterol lowering, anti-bacterial, anti-fungal, anti-inflammatory, analgesic, and wound healing benefits.

\subsection{Cardio- and Hepatoprotective Benefits}

Muralidharam et al. [48] observed that carrot seed extract offers cardioprotection and muscle contraction regulation in isoproterenol-induced myocardial infarction in rats by maintaining membrane bound enzymes. From these results investigators concluded that the carrot seed extract might have inotropic effects. Notably, levels of serum aspartame transaminase, alanine transaminase and lactate dehydrogenase were significantly lower in carrot seed extract fed rats.

Singh et al. [49] reported the hypolipidemic activity of carrot seeds in rats. It was observed that rats fed with carrot seeds showed a reduction in the total cholesterol and triglyceride HLD and VLDL as compared with the control group of rats. Aydin et al. [50] studied the effects of carrot seed extract on thioacetamide, the potent hepatotoxic amide. Normally it facilitates increased synthesis of guanine and cytosine rich RNA with concomitant decrease in ribosomal RNA. The investigators observed and inverse correlation in thioacetamide-induced rise of liver markers levels after administration of carrot seed extract. This favorable effect is an indicator of the liver membrane stabilizing effect of the seed extract. Moreover, a significant rise in levels of antioxidant enzymes such as SOD, catalase, and glutathione peroxidase was also reported. Recently, Singh et al. [51] studied the in vitro antioxidant and hepatoprotective activity of methanolic extracts of carrot seeds. This study concluded that the hepatoprotective activity of the carrot seed extract was due to the antioxidant potential of carrot seed extract. Rezaei-Maghadam et al. [52] reported also the antioxidant activity and inhibit peroxidation activity in the liver tissue of ethanolic carrot seed extracts based on in vivo experiments in rats. Their study showed that the regular intake of ethanolic carrot seed extracts by rats through the diet can improve antioxidant status and inhibit peroxidation activity in the liver tissue

\subsection{Cognitive Dysfunction and Cholesterol Lowering Benefits}

Cognition includes all aspects of perceiving, learning, thinking and remembering. The cognitive dysfunctions include delirium, behavioral disorders and dementia. Cognitive impairment is the leading cause of neurodegenerative diseases such as Alzheimer's disease and dementia in elderly individuals. It is characterized by progressive memory loss and personality defects accompanied by structural abnormalities in the brain like speech disorder and loss of space orientation. Vasudevan et al. [53] reported that carrot seed extract reversed the memory 
deficits in scopolamine (or diazepam)-induced amnesia in young mice. These investigators concluded that administration of carrot seed extract reduced brain acetylcholinesterase activity and cholesterol levels in mice (acetylcholine synthesis is mediated by choline and acetyl coenzyme A in the presence of the enzyme choline acetyltransferase). Furthermore they observed that the ethanolic extract of carrot seeds improved the retention capacity of aged mice, when administrated orally for 7 days. Later in another study Vasudevan et al. [54] confirmed anti-dementia potential of carrot seed extracts in rats. Carrot seed extract reversed scopolamine, diazepam or ageing-induced amnesia when administered for seven days in rats. They concluded that carrot seed extracts prove to be a usefull anti-Alzheimer agent, in view of its memory enhancing property observed in this study. These results are in agreement with Indian Materia Medica that makes a mention of carrot seeds as a brain tonic [55]. Previously, Gambhir et al. [56] showed that choline-rich quaternary base chlorides separated from carrot seeds exhibit procholinergic activity. Vasudevan et al. [53] concluded that enhanced cholinergic transmission resulted from increased acetylcholine synthesis in the brain due to abundant availability of choline and reduction of brain cholinesterase activity. These effects in aged and young mice resulted in cognitive and memory improvement and cholesterol-lowering benefits and might prove helpful in the management of cognitive dysfunctions in elderly human patients.

\subsection{Anti-Bacterial and Anti-Fungal Benefits}

Rossi et al. [57] reported that the essential oil obtained from aerial parts of the of wild carrot showed inhibitory action against the enteropathogen Campylobacter jejuni. Also phenylpropanoids, such as methylisoeugenol and elemicin, from essential oil also exerted antimicrobial effect against Campylobacter coli and C. lari strains. These authors found that an aromatic ring and a double bond on the side chain of both methylisoeugenol and elemicim might be the responsible for the anti-microbial effects.

Misiaka et al. [58] reported that carrot seed oil extracts exhibited moderate inhibitory effects on mycelia growth of Alternaria alternate (one of the most popular phytotoxic fungi infesting the carrot plant), isolated from the surface of carrot seeds cultivar Perfekcja. Experiments, namely with the chemical compounds, carotol, $\beta$-caryophyllene, and daucol were carried out to find out whether the observed activity was derived from the action of carotol alone or from a synergistic action. Carotol significantly inhibited the growth of the fungi and reduced the colony radial size. Meanwhile, the inhibitory effect produced by daucol was comparatively less than carotol. No effect was exerted by $\beta$-caryophyllene. The results suggested that carotol is the main agent responsible for the anti-fungal activity of carrot seed oil extracts.

Another assay assessing the anti-bacterial effect was conducted by Kumarasamy et al. [59] using the compounds obtained from methanolic extract of wild carrot seeds. Luteolin, luteolin 3'-O- $\beta$-D-glucopyranoside, and luteolin 4'-O- $\beta$-glucopyranoside are the major flavones isolated from methanolic extract. These authors found that luteolin exerted anti-bacterial activity against Bacillus cereus and Citrobacter freundii. Meanwile luteolin 3'-O-glucoside showed antibacterial activity against B. cereus and Lactobacillus plantarum. Similarily, growth of Staphylococcus aureus and Escherichia coli were inhibited by both luteolin and its 4'-O-glucoside. Moreover, in the 2.2-diphenyl-1-picrylhydrazyl (DPPH) assay luteolin showed greater radical scavenging activity.

\subsection{Anti-Inflammatory and Analgesic Benefits}

The anti-inflammatory and analgesic effects of carrot seed extract have been reported experimentally. Vasudevan et al. [60] suggested that carrot seeds possess anti-inflammatory effect. In their research paw edema was induced in rats using carrageenan histamine, and serotonin; and arthritis was induced using folmaldehyde. Surprisingly, the disease condition decreased in rats fed with a high dose of carrot seed extract. Furthermore, in order to assess the carot's analgesic activity, writing effect was induced by intra-peritoneal injection. There was a significant reduction in writhing effect after the administration of carrot seed extract. In another study Mornin et al. [61] found that carrot seed extract compounds (2,4,5-trimethoxybenzaldehyde, oleic acid, trans-asarone and geraniol) has anti-inflammatory properties due to the inhibition of cyclooxygenase enzymes and provided antiinflammatory benefits that were significant even when compared to anti-inflammatory drugs like Aspirin, Ibuprofen, Naproxen and Celebrex.

\subsection{Fertility Benefits}

The fertily effect of carrot seed extract is gender dependent. Pharmacological studies showed that carrot seeds 
exhibit anti-fertility properties in females [62]-[64]. In contrast Nouri et al. [65] reported that carrot seed extract induces spermatogenesis in male rats. They observed that rats fed with carrot seed extract recovered from gentamicin-induced reproductive toxicity and displayed enhanced spermatogenesis. Thus, carrot seed extract was able to induce spermatogenesis and cauda epididymal sperm reserves. The probable biochemical mechanism behind the effect is through the elevation of testosterone levels in male rats. Besides carrot seed extracts are rich in antioxidants and therefore the elevation in cauda epididymal sperm reserves may be also attributed to its antioxidant effect.

\section{Outlook}

Carrot has remarkable nutritional and health benefits. There are good reasons to include carrots in human diet, since they are enriched with carotenoids, phenolic compounds, polyacetylenes, and vitamins and by this reason they may help reduce the risk of some diseases. Experimental evidence has reported that these carrot compounds exert antioxidative, anticarcinogenic, and immunoenhancer effects. Anti-diabetic, cholesterol and cardiovascular disease lowering, anti-hypertensive, hepatoprotective, renoprotective, and wound healing benefits of carrot have also been reported. The mechanism by which these carrot compounds decrease the risk of some diseases is complex and sometimes largely unknown.

The cardio- and hepatoprotective, anti-bacterial, anti-fungal, anti-inflammatory, and analgesic effects of carrot seed extracts are also noteworthy.

\section{References}

[1] Simon, P.W. (2000) Domestication, Historical Development and Modern Breeding of Carrot. Plant Breeding Reviews, 19, $157-190$.

[2] Dias, J.S. (2012) Major Classes of Phytonutriceuticals in Vegetables and Health Benefits: A Review. Journal of Nutritional Therapeutics, 1, 31-62.

[3] Dias, J.S. (2012) Nutritional Quality and Health Benefits of Vegetables: A Review. Food and Nutrition Sciences, 3, 1354-1374. http://dx.doi.org/10.4236/fns.2012.310179

[4] Sun, T., Simon, P.W. and Tamumuhardjo, S.A. (2009) Antioxidant Phytochemicals and Antioxidant Capacity of Biofortified Carrots (Daucus carota L.) of Various Colors. Journal of Agricultural and Food Chemistry, 57, $4142-4147$. http://dx.doi.org/10.1021/jf9001044

[5] Simon, P.W. and Goldman, I.L. (2007) Carrot. In: Sing, R.J., Ed., Genetic Resources, Chromosome Engineering, and Crop Improvement, CRC Press, Boca Raton, 497-516.

[6] Van het Hof, K.H., West, C.E., Weststrate, J.A. and Hautvast, J.G. (2000) Dietary Factors That Affect the Bioavailability of Carotenoids. J. Nutr., 130, 503-506.

[7] Ching, L.S. and Mohamed, S. (2001) Alpha-Tocopherol Content of 62 Edible Tropical Plants. Journal of Agricultural and Food Chemistry, 49, 3101-3105. http://dx.doi.org/10.1021/jf000891u

[8] Lila, M.A. (2004) Anthocyanins and Human Health: An in Vitro Investigative Approach. Journal of Biomedicine and Biotechnology, No. 5, 306-313. http://dx.doi.org/10.1155/S111072430440401X

[9] Horbowicz, M., Kosson, R., Grzesiuk, A. and Bski, H.D. (2008) Anthocyanins of Fruits and Vegetables-Their Occurrence Analysis and Role in Human Nutrition. Vegetable Crops Research Bulletin, 68, 5-22.

[10] Zhang, D. and Hamauzu, Y. (2004) Phenolic Compounds and Their Antioxidant Properties in Different Tissues of Carrots (Daucus carota L.). Journal of Food, Agriculture and Environment (JFAE), 2, 95-100.

[11] Gonçalves, E.M., Pinheiro, J., Abreu, M. and Silva, C.L. (2010) Carrot (Daucus carota L.) Peroxidase Inactivation, Phenolic Content and Physical Changes Kinetics Due to Blanching. Journal of Food Engineering, 97, 574-581. http://dx.doi.org/10.1016/j.jfoodeng.2009.12.005

[12] Lund, E.D. and White, J.M. (1990) Polyacetylenes in Normal and Waterstressed “Orlando Gold” Carrots (Daucus carota). Journal of the Science of Food and Agriculture, 51, 507-516. http://dx.doi.org/10.1002/jsfa.2740510407

[13] Hansen, L., Hammershoy, O. and Boll, P.M. (1986) Allergic Contact Dermatitis from Falcarinol Isolated from Schaffera arboricola. Contact Dermatitis, 14, 91-93. http://dx.doi.org/10.1111/j.1600-0536.1986.tb01167.x

[14] Ahmed, A.A., Bishr, M.M., El-Shanawany, M.A., Attia, E.Z., Ross, S.A. and Pare, P.W. (2005) Rare Trisubstituted Sesquiterpenes Daucanes from wild Daucus carota. Phytochemistry, 66, 1680-1681. http://dx.doi.org/10.1016/j.phytochem.2005.05.010

[15] Fu, H.W., Zhang, L., Yi, T., Feng, Y.L. and Tian, J. (2010) Two New Guaniane-Type Sesquiterpenoids from the Fruits of Daucus carota L. Fitoterapia, 81, 443-446. http://dx.doi.org/10.1016/j.fitote.2009.12.008 
[16] Czepa, A. and Hofmann, T. (2003) Structural and Sensory Characterization of Compounds Contributing to the Bitter Off-Taste of Carrots (Daucus carota L.) and Carrot Puree. Journal of Agricultural and Food Chemistry, 51, 3865-3872. http://dx.doi.org/10.1021/jf034085+

[17] Acharya, U.R., Mishra, M., Patro, J. and Panda, M.K. (2008) Effect of Vitamins C and E on Spermatogenesis in Mice Exposed to Cadmium. Reproductive Toxicology, 25, 84-88. http://dx.doi.org/10.1016/j.reprotox.2007.10.004

[18] Guerrera, M.P., Volpe, S.L. and Mao, J.J. (2009) Therapeutic Uses of Magnesium. American Family Physician, 80, 157-162.

[19] Bartlett, H.E. and Eperjesi, F. (2008) Nutritional Supplementation for Type 2 Diabetes: A Systematic Review. Ophthalmic and Physiological Optics, 28, 503-523. http://dx.doi.org/10.1111/j.1475-1313.2008.00595.x

[20] Kim, D.J., Xun, P., Liu, K., Loria, C., Yokota, K., Jacobs Jr., D.R. and He, K. (2010) Magnesium Intake in Relation to System Inflammation, Insulin Resistance, and the Incidence of Diabetes. Diabetes Care, 33, 2604-2610. http://dx.doi.org/10.2337/dc10-0994

[21] Zaini, R., Clench, M.R. and Maitre, C.L. (2011) Bioactive Chemicals from Carrot (Daucus carota) Juice Extracts for the Treatment of Leukemia. Journal of Medicinal Food, 14, 1303-1312. http://dx.doi.org/10.1089/jmf.2010.0284

[22] Darroudi, F., Targa, H. and Natarajan, A.T. (1988) Influence of Dietary Carrot on Cytostatic Drug Activity of Cyclophosphamide and Its Main Directly Acting Metabolite: Induction of Sister-Chromatid Exchanges in Normal Human Lymphocytes, Chinese Hamster Ovary Cells, and Their DNA Repair-Deficient Cell Lines. Mutation Research, 198, 327-335. http://dx.doi.org/10.1016/0027-5107(88)90010-3

[23] Larsen, M.K., Christensen, L.P., Vach, W., Hoitinga, R.J. and Brant, K. (2005) Inhibitory Effects of Feeding with Carrots or (-)-Falcarinol on Development of Azoxymethame-Induced Preneoplastic Lesions in the Rat Colon. Journal of Agricultural and Food Chemistry, 53, 1823-1827. http://dx.doi.org/10.1021/jf048519s

[24] Purup, S., Larsen, E. and Christesen, L.P. (2009) Differential Effects of Falcarinol and Related Aliphatic C 17 -Polyacetylenes on Intestinal Cell Proliferation. Journal of Agricultural and Food Chemistry, 57, 8290-8296. http://dx.doi.org/10.1021/jf901503a

[25] Matsunaga, H., Katano, M., Yamanoto, H., Fujito, H. and Takata, M.M. (1990) Cytotoxic Activity of Polyacetylene Compouds in Panax ginseng C.A. Meyer. Chemical and Pharmaceutical Bulletin, 38, 3480-3482. http://dx.doi.org/10.1248/cpb.38.3480

[26] Saita, T., Katano, M., Matsunaga, H., Yamamsoto, H., Fujito, H. and Mori, M. (1993) The First Specific Antibody against Cytotoxic Polyacetylenic Alcohol, Panaxysol. Chemical and Pharmaceutical Bulletin, 41, 549-552. http://dx.doi.org/10.1248/cpb.41.549

[27] Ekam, V.S., Udosen, E.O. and Chighu, A.E. (2006) Comparative Effect of Carotenoid Complex from Goldenneo-Life Dynamite and Carrot Extracted Carotenoids on Immune Parameters in Albino Wistar Rats. Nigerian Journal of Physiological Sciences, 21, 1-4.

[28] Swamy, K.R., Nath, P. and Ahuja, K.G. (2014) Vegetables for Human Nutrition and Health. In: Nath, P., Ed., The Basics of Human Civilization-Food, Agriculture and Humanity, Volume-II-Food, Prem Nath Agricultural Science Foundation (PNASF), Bangalore \& New India Publishing Agency (NIPA), New Delhi, 145-198.

[29] Pisani, P., Berrino, F., Macaluso, M., Pastorino, U., Crosignani, P. and Baldasseroni, A. (1986) Carrots, Green Vegetables and Lung Cancer: A Case-Control Study. International Journal of Epidemiology, 15, 463-468. http://dx.doi.org/10.1093/ije/15.4.463

[30] Wu, K., Erdman Jr., J.W., Schwartz, S.J., Platz, E.A., Leitzmann, M., Clinton, S.K., DeGroff, V., Willett, W.C. and Giovannucci, E. (2004) Plasma and Dietary Carotenoids, and the Risk of Prostate Cancer: A Nested Case-Control Study. Cancer Epidemiology Biomarkers \& Prevention, 13, 260-269. http://dx.doi.org/10.1158/1055-9965.EPI-03-0012

[31] Hung, R.J., Zhang, Z.F., Rao, J.Y., Pannack, A., Reuter, V.E., Heber, D. and Lu, Q.Y. (2006) Protective Effects of Plasma Carotenoids on the Risk of Bladder Cancer. Journal of Urology, 176, 1192-1197. http://dx.doi.org/10.1016/j.juro.2006.04.030

[32] Brazionis, L., Rowley, K., Itsiopoulos, C. and O’Dea, K. (2009) Plasma Carotenoids and Diabetic Retinopathy. The British Journal of Nutrition, 101, 270-277. http://dx.doi.org/10.1017/S0007114508006545

[33] USDHHS (US Department of Health and Human Services) and USDA (US Department of Agriculture) (2010) Dietary Guidelines for Americans. 7th Edition, US Government Printing Office, Washington DC.

[34] Coyne, T., Ibiebele, T.I., Baade, P.D., Dobson, A., McClintock, C., Dunn, S., Leonard, D. and Shaw, J. (2005) Diabetes Mellitus and Serum Carotenoids: Findings of a Population-Based Study in Queensland, Australia. The American Journal of Clinical Nutrition, 82, 685-693.

[35] Chau, C.F., Chen, C.H. and Lee, M.H. (2004) Comparison of the Characteristics, Functional Properties, and in Vitro Hypoglycemic Effects of Various Carrot Insoluble Fiber-Rich Fractions. Lebensmittel-Wissenshaff und Technologie, 
37, 155-160. http://dx.doi.org/10.1016/j.lwt.2003.08.001

[36] Saura-Calixto, F. and Goñi, I. (2006) Antioxidant Capacity of the Spanish Meditarrean Diet. Food Chemistry, 94, 442447. http://dx.doi.org/10.1016/j.foodchem.2004.11.033

[37] Saura-Calixto, F., Serrano, J. and Goñi, I. (2007) Intake and Bioaccessibility of Total Polyphenols in a Whole Diet. Food Chemistry, 101, 492-501. http://dx.doi.org/10.1016/j.foodchem.2006.02.006

[38] Harold, R., Reeves, R., Blze, M., Guthrie, R. and Guthrie, D. (1985) Effect of Dietary Fiber in Insulin-Dependent Diabetics: Insulin Requirements and Serum Lipids. Journal of the American Dietetic Association, 85, 1455-1461.

[39] Poudyal, H., Panchal, S. and Brown, L. (2010) Comparison of Purple Carrot Juice and $\beta$-Carotene in a High-Carbohydrate, High-Fat Diet-Fed Rat Model of the Metabolic Syndrome. British Journal of Nutrition, 104, 1322-1332. http://dx.doi.org/10.1017/S0007114510002308

[40] Nicolle, C., Cardinault, N., Aprikian, O., Busserolles, J., Grolier, P., Rock, E., Demigné, C., Mazur, A., Scalbert, A., Amouroux, P. and Rémésy, C. (2003) Effect of Carrot Intake on Cholesterol Metabolism and on Antioxidant Status in Cholesterol-Fed Rat. European Journal of Nutrition, 42, 254-261. http://dx.doi.org/10.1007/s00394-003-0419-1

[41] Gramenzi, A., Gentile, A., Fasoli, M., Negri, E., Parazzini, F. and La Vecchia, C. (1990) Association between Certain Foods and Risk of Acute Myocardial Infarction in Women. BMJ, 300, 771-773.

http://dx.doi.org/10.1136/bmj.300.6727.771

[42] Griep, L.M., Verschuren, W.M., Kromhout, D., Ocké, M.C. and Geleijnse, J.M. (2011) Colors of Fruit and Vegetables and 10-Year Incidence of CHD. British Journal of Nutrition, 106, 1562-1569. http://dx.doi.org/10.1017/S0007114511001942

[43] Gilani, A.H., Shaheeri, F., Saeed, S.A., Bibi, S., Irfamillah-Sadiq, M. and Faiz, S. (2000) Hypotensive Action of Coumarin Glycoside from Daucus carot. Phytomedicine, 7, 423-426. http://dx.doi.org/10.1016/S0944-7113(00)80064-1

[44] Bishayee, A., Sarkar, A. and Chatterjee, M. (1995) Hepatoprotective Activity of Carrot (Daucus carota L.) against Carbon Tetrachoride Intoxication in Mouse Liver. Journal of Ethnopharmacology, 47, 69-74. http://dx.doi.org/10.1016/0378-8741(95)01254-B

[45] Mills, J.P., Simon, P.W. and Tanumihardjo, S.A. (2008) Biofortified Carrot Intake Enhances Liver Antioxidant Capacity and Vitamin A Status in Mongolian Gerbils. Journal of Nutrition, 138, 1692-1698.

[46] Mital, P.R., Laxman, P.J. and Ramesshvar, P.K. (2011) Protective Effect of Daucus carota Root Extract against Ischemia Reperfusion Injury in Rats. Pharmacology, 1, 432-439.

[47] Patil, M.V., Kandhare, A.D. and Bhise, S.D. (2012) Pharmacological Evaluation of Ethanolic Extract of Daucus carota Linn Root Formulated Cream on Wound Healing Using Excision and Incision Wound Model. Asian Pacific Journal of Tropical Biomedicine, 2, S646-S655. http://dx.doi.org/10.1016/S2221-1691(12)60290-1

[48] Muralidharan, P., Balamurugan, G. and Kumar, P. (2008) Inotropic and Cardioprotective Effects of Daucus carota Linn. on Isoproterenol-Induced Myocardial Infarction. Bangladesh Journal of Pharmacology, 3, 74-79.

[49] Sing, K., Dhongade, H., Sing, N. and Kashyap, P. (2010) Hypolipidemic Activity of Ethanolic Extract of Daucus carota Seeds in Normal Rats. International Journal of Biomedical and Advance Research, 1, 73-80. http://dx.doi.org/10.3329/bjp.v3i2.849

[50] Aydin, A.F., Kiraz, Z.K., Abbasoghu, S.D., Gulluoglu, M., Uysal, M. and Toker, N.K. (2010) Effect of Carnosine against Thioacetamide-Induced Liver Cirrhosis in Rat. Peptides, 31, 67-71. http://dx.doi.org/10.1016/j.peptides.2009.11.028

[51] Singh, K., Singh, N., Chandy, A. and Maniganha, A. (2012) In Vivo Antioxidant and Hepatoprotective Activity of Methanolic Extracts of Daucus carota Seeds in Experimental Animals. Asian Pacific Journal of Tropical Biomedicine, 2, 385-388. http://dx.doi.org/10.1016/S2221-1691(12)60061-6

[52] Rezaei-Maghadam, A., Mohajeri, D., Rafiei, B., Dizaji, R., Azhdari, A., Yegomehzad, M., Shahidi, M. and Mazani, M. (2012) Effect of Tumeric and Carrot Seed Extracts on Serum Liver Biomakers and Hepatic Lipid Peroxidation, Antioxidant Enzymes and Total Antioxidant Status in Rats. Bioimpacts, 2, 151-157.

[53] Vasudevan, M. and Parle, M. (2006) Pharmalogical Evidence for Potential of Daucus carota in the Management of Cognitive Dysfunctions. Biological \& Pharmaceutical Bulletin, 29, 1154-1161. http://dx.doi.org/10.1248/bpb.29.1154

[54] Vasudevan, M., Parle, M., Ramasamy, K. and Majeed, A.B.A. (2010) Anti-Dementia Potential of Daucus carota Seed Extracts in Rats. Pharmacologyonline, 1, 552-565.

[55] Nadkarni, K.M. (1976) Indian Material Medica. Vol. I, Popular Prokashan, Bombay.

[56] Gambhir, S.S., Sanyal, A.K., Sen, S.P. and Das, P.K. (1966) Studies on Daucus carota Linn. II. Cholinergic Activity of the Quaternary Base Isolated from Water-Soluble Fraction of Alcoholic Extracts of Seeds. Indian Journal of Medical Research, 54, 1053-1056. 
[57] Rossi, P.G., Bao, L., Luciani, A., Panighi, J., Desjobert, J.M., Costa, J., Casanova, J., Bolla, J.M. and Berti, L. (2007) (E)-Methylisoeugenol and Elemicin: Antibacterial Components of Daucus carota L. Essential Oils against Campylobacter jejuni. Journal of Agricultural and Food Chemistry, 55, 7332-7336. http://dx.doi.org/10.1021/jf070674u

[58] Misiaka, I.J., Lipoka, J., Nowakowska, E.M., Wieczoreka, P.P., Mlynarz, P. and Kafarski, P. (2004) Antifungal Activity of Carrot Seed Oil and Its Major Sesquiterpene Compounds. Zeitschrift für Naturforschung, 59, 791-796.

[59] Kumarasamy, Y., Nahar, L., Byres, M., Delazar, A. and Sarker, S.D. (2005) The Assessment of Biological Activities Associated with the Major Constituents of the Methanol Extract of “Wild Carrot” (Daucus carota L.) Seeds. Journal of Herbal Pharmacotherapy, 5, 61-72.

[60] Vasudevan, M., Gunnam, K.K. and Parle, M. (2006) Anticonceptive and Anti-Inflammatory Properties of Daucus carota Seeds Extract. Journal of Health Science, 52, 598-606. http://dx.doi.org/10.1248/jhs.52.598

[61] Mornin, R.A., De Witt, D.L. and Nair, M.G. (2003) Inhibition of Cyclooxygenase (COX) Enzymes by Compounds from Daucus carota L. Seeds. Phytotherapy Research, 17, 976-979. http://dx.doi.org/10.1002/ptr.1296

[62] Bhatnagar, U. (1995) Poscoital Contraceptive Effects of an Alcoholic Extract of the Daucus carota Linn Seed in Rats. Clinical Drug Investigation, 9, 30-36. http://dx.doi.org/10.2165/00044011-199509010-00006

[63] Majumder, P.K., Dasgupta, S., Mukhopadhaya, R.K., Majundar, U.K. and Gupta, M. (1997) Anti-Steroidogenic Activity of the Petroleum Ether Extract and Fraction 5 (Fatty Acids) of Carrot (Daucus carota L.) Seeds in Mouse Ovary. Journal of Ethnopharmacology, 57, 209-2012. http://dx.doi.org/10.1016/S0378-8741(97)00056-1

[64] Majundar, U.K., Gupta, M. and Patro, V.J. (1998) Studies on Anti-Fertility of Methanolic Extract of Daucus carota Linn. Seeds. Indian Journal of Natural Products, 14, 33-37.

[65] Nouri, M., Khaki, A., Azar, F.F. and Rashidi, M.R. (2009) The Protective Effects of Carrot Seed Extract on Spermatogenesis and Cauda Epididymal Sperm Reserves in Gentamicin Treated Rats. Yakhteh Medical Journal, 11, 327-333. 
Scientific Research Publishing (SCIRP) is one of the largest Open Access journal publishers. It is currently publishing more than 200 open access, online, peer-reviewed journals covering a wide range of academic disciplines. SCIRP serves the worldwide academic communities and contributes to the progress and application of science with its publication.

Other selected journals from SCIRP are listed as below. Submit your manuscript to us via either submit@scirp.org or Online Submission Portal.
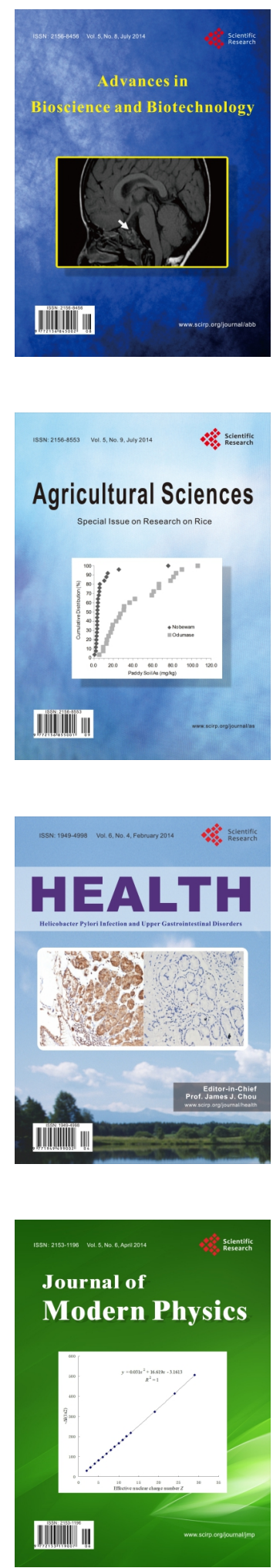
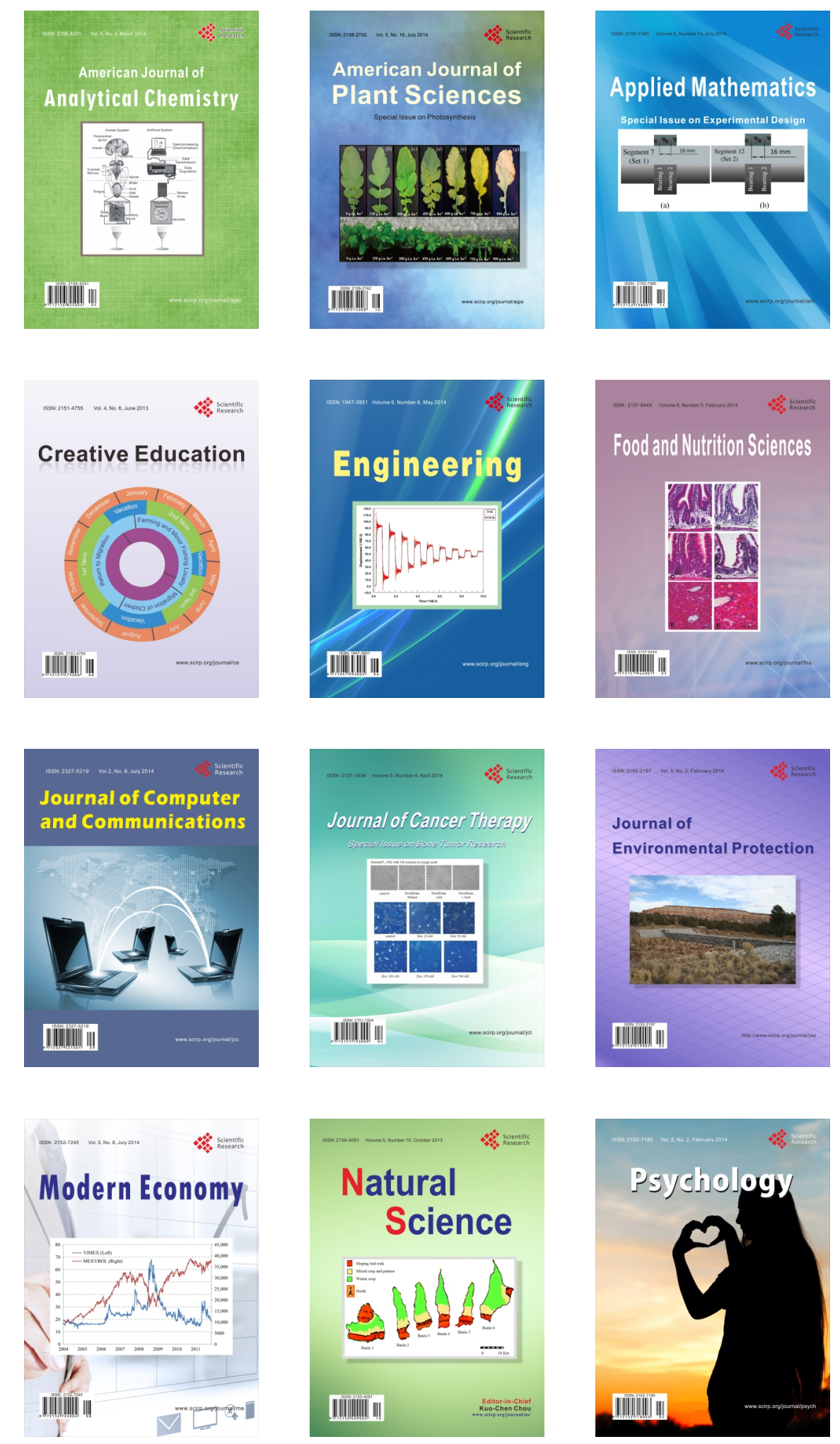